Vol 11, Issue 12, 2018

\title{
CHARACTERIZATION OF INULIN FROM BLACK SALSIFY (SCORZONERA HISPANICA L.) FOR FOOD AND PHARMACEUTICAL PURPOSES
}

\author{
NADEZHDA PETKOVA* \\ Department of Organic Chemistry and Inorganic Chemistry, University of Food Technologies, 26 Maritza Blvd., Plovdiv, 4002, Bulgaria. \\ Email: petkovanadejda@abv.bg
}

Received: 03 July 2018, Revised and Accepted: 30 July 2018

\begin{abstract}
Objective: The aim of the current study was to evaluate the black salsify (Scorzonera hispanica L.) as a potential source of inulin and to characterize the physicochemical properties of isolated polysaccharide.

Methods: The carbohydrate content in its roots and leaves was analyzed by high-performance liquid chromatography with refractive index detection (HPLC-RID) method. Microwave-assisted extraction was performed for isolation of inulin from black salsify roots. The obtained polysaccharide was characterized by HPLC-RID method, HPLC size-exclusion chromatography, and Fourier transformed-infrared spectroscopy. Functional properties as swelling capacity, solubility, and water-holding and oil-holding capacities (OHCs) were also evaluated.
\end{abstract}

Results: Black salsify (S. hispanica L.) roots were evaluated as a rich source of inulin (22\% dw) and 1-kestose (6.25 g/100 g dw). The isolated inulin (yield 20\%) was characterized with average degree of polymerization 17, with polydispersity index (1.04) that was near to medium-chained inulin. This polysaccharide showed better $\mathrm{OHC}$ than water-holding capacity, and it was characterized with swelling capacity $0.5 \mathrm{ml} / \mathrm{g}$ sample.

Conclusion: For the first time, inulin was isolated from black salsify roots. The chemical characterization of inulin reveals the potential of this plant to be used as a valuable source of this polysaccharide for future application in food technology and pharmaceutical industry for dietary fibers, stabilizer, and coating agent.

Keywords: Black salsify (Scorzonera hispanica L.), Roots, Inulin.

(C) 2018 The Authors. Published by Innovare Academic Sciences Pvt Ltd. This is an open access article under the CC BY license (http://creativecommons. org/licenses/by/4. 0/) DOI: http://dx.doi.org/10.22159/ajpcr.2018.v11i12.28262

\section{INTRODUCTION}

Inulin is a biopolymer consisted of D-fructose monomers connected by $\beta$ - $(2 \rightarrow 1)$ linkages and it terminates with a D-glucose residue linked to D-fructose with an $\alpha-(1 \rightarrow 2)$ linkage. It possesses an extensive range of therapeutic uses because of its pharmacological inertness. Inulin has been extensively used as a drug delivery agent, as a diagnostic/analytical tool, or as a dietary fiber with additional health benefits due to its rapid water solubility, low friability, and stability against gastric and intestinal enzymes [1-3]. Its isoforms (especially gamma- and delta-inulins) are successfully used in pharmacy as vaccine adjuvants [4-6]. Many researchers have focused on inulin as a drug carrier for colon-targeted drug delivery [1,3,6,7].

Inulin can be used for encapsulation purposes, especially in oregano oil [8], catechins, or thyme extracts, as an active ingredient $[9,10]$ or as a coating material of tablets, capsules, tablet binder, and a vaccine stabilizer [1,11]. Inulin has also been used to stabilize membranes, proteins, and several pharmaceutically relevant systems, unstable drugs $[1,2]$. It possessed solubility better than drugs and this property is dependent on inulin molecular weight [12].

Therefore, the plant sources of inulin are with a significant importance for its production. Many researches demonstrated isolation of inulin in good yields from different plant materials [13-15]. In our previous reports, inulin from Jerusalem artichoke, common chicory, dahlia, and elecampane was isolated by "green methods" of extraction - microwave and ultrasonic irradiation [16-19]. The search of good yields and sustainable plant sources of inulin attracts attention to the vegetable black salsify (Scorzonera hispanica L.).

Black salsify, known as Spanish salsify, scorzonera, salsify, kozelets, black oyster plant, serpent root, viper's herb, and viper's grass, is a perennial plant from the subgenus Scorzonera, Asteraceae family [20-23]. It is native for Europe, North Africa, and Asia, and it has been introduced to North America [23]. It is cultivated as a crop plant because of its taproots not only in the Mediterranean region but also in other temperate and subtropical areas, as well as at higher altitudes in the tropics [25].

The leaves are usually linear to linear-elliptic or lanceolate, more rarely also ovate, with parallel veins, not divided, base with semiamplexicaul usually persistent sheath, margin entire, flat, or sometimes undulate [22-23].They are rich in vitamin C, but lack inulin [24], and they are eaten fresh or blanched, especially in salads [25]. The roots are long, white, milky inside, and blackish outside [26,27]. They are edible, consumed processed and canned [28] or eaten fresh (raw, seasoned, or cooked). It is cooked as a vegetable and also used dried. They are roasted as coffee substitute [22] because of their high levels of inulin roots that are very appropriate for diabetic diets [26]. Roots contain valuable content of polysaccharides (about 17\%), mainly inulin [29] $13-16 \%$, pectin $-3-5 \%$, and fiber $-1.5-2.5 \%$ [27]. Powder of black salsify roots (3-4\%) was used in ice cream fortification with fibers [27]. It was also reported that inulin content in $S$. hispanica roots reached values $8-21 \% d w$, as the degree of polymerization (DP) $>5$ dominated and reached $75 \%[13,30]$. With $300 \mathrm{~g}$ cooked dish of this vegetable, 6-9 $\mathrm{g}$ of daily intake of inulin was assured [13].

However, only data for inulin content in the roots are available, without any studies about inulin isolation and its physicochemical and spectral characteristic. Therefore, the purpose of the current study was to evaluate black salsify ( $S$. hispanica L.) as a potential source of inulin and to characterize the physicochemical properties of the isolated polysaccharide for future application in food and pharmacy. 


\section{METHODS}

\section{Chemicals, reagents, and standards}

All chemicals and reagents used were analytical grade.

\section{Plant material}

Black salsify (S. hispanica L.) seeds were purchased from an agriculture store (Plovdiv, Bulgaria) produced under trademark Florian (Romania). The seeds were planted during April 2017. Black salsify leaves and roots were harvest during November 2017 (Plovdiv, Bulgaria). The plant samples were checked and identified as black salsify (S. hispanica L.) by the botanists from Agriculture University (Plovdiv, Bulgaria). The leaves and roots were washed with tap water to remove any impurities. The leaves were dried at room temperature. The roots were chopped into parts with sizes $2-3 \mathrm{~cm}$ and then dried in the oven at $40^{\circ} \mathrm{C}$. The plant materials were finely ground in a laboratory homogenizer to powder and sieved through $0.5 \mathrm{~mm}$. The leaves and roots were kept in tightly closed containers for further analysis.

\section{Extraction procedure}

Plant materials form black salsify (leaves and roots, respectively) were extracted with $\mathrm{d}$. $\mathrm{H}_{2} \mathrm{O}$ in solid-to-liquid ratio $1: 10(\mathrm{w} / \mathrm{v})$. The extraction procedure was performed in an ultrasonic bath (SIEL, Gabrovo, Bulgaria, $35 \mathrm{kHz}$ and $300 \mathrm{~W}$ ) for $20 \mathrm{~min}$, at $75^{\circ} \mathrm{C}$ in duplicate [31]. The obtained extracts were filtered and the residues were extracted again under the same conditions. The volume of combined extracts was measured and they were used for high-performance liquid chromatography (HPLC) analysis of carbohydrates.

\section{HPLC analysis of inulin and sugars}

Chromatographic separation was performed on an HPLC instrument Elite Chrome Hitachi, coupled with a refractive index detector (RID) Chromaster 5450. The separation was done on a Shodex ${ }^{\circledR}$ Sugar SP0810 (300 $\mathrm{mm} \times 8.0 \mathrm{~mm}$ i.d.) with $\mathrm{Pb}^{2+}$ and a guard column Shodex SP-G ( $5 \mu \mathrm{m}, 6 \mathrm{~mm} \times 50 \mathrm{~mm}$ ) operating at $85^{\circ} \mathrm{C}$, mobile phase d. $\mathrm{H}_{2} \mathrm{O}$ with flow rate of $1.0 \mathrm{ml} / \mathrm{min}$ and the injection volume $20 \mu \mathrm{l}$ [31].

\section{Isolation of inulin from black salsify (S. hispanica L.)}

The dry black salsify roots were extracted using distilled water in solidto-solvent ratio $1: 10 \mathrm{w} / \mathrm{v}$. The microwave-assisted extraction (MAE) was performed in duplicate in a microwave oven (Daewoo KOR, power $700 \mathrm{~W}$, and $2450 \mathrm{MHz}$ frequency) as duration of each extraction was $5 \mathrm{~min}$. The sample was filtered through nylon cloth and the obtained extracts were cooled to the room temperature. Then, it was precipitated by the addition of four volume $95 \%(\mathrm{v} / \mathrm{v}$ ) ethanol, the sample was cooled at $-18^{\circ} \mathrm{C}$ for $60 \mathrm{~min}$, and the vacuum filtration was performed. The obtained residue was washed with $95 \%$ ethanol and acetone, and it was dried in vacuum oven. The yield was calculated using the following equation (1):

$$
\text { Yield, } \%=\frac{\text { inulin, } g}{\text { weight of dry roots, } g} * 100
$$

\section{Characterization of inulin}

The obtained inulin was characterized by different spectral and chromatographic methods. Melting point of isolated inulin was measured on a melting point Kofler apparatus. The reducing groups were determined by PAHBAH method at $410 \mathrm{~nm}$ [32]. Total fructose content was assayed by resorcinol-thiourea methods at $480 \mathrm{~nm}[16,17]$. The purity of inulin was analyzed by HPLC instrument Elite Chrome Hitachi with a Shodex ${ }^{\circledR}$ Sugar SP0810 (300 mm $\times 8.0 \mathrm{~mm}$ i.d.) with $\mathrm{Pb}^{2+}$ and a guard column, operating at $85^{\circ} \mathrm{C}$, coupled with RID Chromaster 5450. The mobile phase was distilled water with a flow rate of $1.0 \mathrm{~mL} / \mathrm{min}$ and the injection volume was $20 \mu \mathrm{l}$ [31].

\section{Homogeneity and molecular weight of inulin}

Number average molecular weight (Mn) and weight average molecular weight $(\mathrm{Mw})$ of black salsify inulin were evaluated by HPLC size- exclusion chromatography (HPLC-SEC). It was carried out using HPLC chromatograph ELITE LaChrome (VWR Hitachi, Japan) on a column Shodex OH pack 806 M (ID $8 \times 300 \mathrm{~mm}$ ), (Shodex Co., Tokyo, Japan) operating at $30^{\circ} \mathrm{C}$ and an RI detector (VWR Hitachi Chromaster, 5450, Japan). Elution was performed with mobile phase $0.1 \mathrm{M} \mathrm{NaNO}_{3}$ solution with a flow rate of $0.8 \mathrm{~mL} / \mathrm{min}$. Samples were filtered through $0.45 \mu \mathrm{m}$ filter PTFE45/25 mm (Isolab, Germany), and they were injected (20 $\mu \mathrm{l} \mathrm{loop}$ ) at concentration of $3 \mathrm{mg} / \mathrm{ml}$. The standard curve built with different pullulans was used for the calculations. Polydispersity index of inulin was calculated as the ratio of the two molecular weights (Mw/Mn) [33,34]. The DP was calculated by dividing the mass of the oligomer to the anhydrofructose unit (162 g/mol) [14].

\section{Fourier transformed-infrared (FTIR) spectroscopy}

The FT-IR spectrum of inulin isolated by MAE was recorded on a Nicolet FT-IR Avatar Nicolet (Thermo Science, USA). Inulin sample (5 mg) was pilleted in $\mathrm{KBr}$. All spectra were collected in the range of 4000-400 $\mathrm{cm}^{-1}$ with a resolution of $4 \mathrm{~cm}^{-1}$ after 132 scans, and the absorption was reported in wavenumbers $\left(\mathrm{cm}^{-1}\right)$.

\section{Functional properties}

\section{Swelling properties}

Swelling properties of black salsify inulin were evaluated as previously described [35]. Inulin (100 mg) was hydrated with distilled water $(10 \mathrm{ml})$ in a calibrated cylinder $(1.5 \mathrm{~cm}$ in diameter $)$ at room temperature. After equilibration $(18 \mathrm{~h})$, the bed volume was recorded and expressed as volume per g original substrate dry weight [35].

\section{Solubility}

Inulin (100 mg) was suspended in distilled water (30 ml), stirred for $3 \mathrm{~h}$ at room temperature and then it was centrifuged $(3000 \mathrm{rpm})$. The supernatant was discarded. The pellets were dried at $105^{\circ} \mathrm{C}$ to constant weight, and water-insoluble parts were determined from loss in sample weight during extraction [35].

Water-holding capacity (WHC) and oil-holding capacities (OHC) Water-holding and oil-holding capacities of inulin were determined in duplicate [35]. Inulin $(0.1 \mathrm{~g})$ was put into tared $50 \mathrm{ml}$ polypropylene centrifuge tubes to which $10 \mathrm{ml}$ deionized water or sunflower oil was added, respectively. The tube was capped and was vigorously mixed. The samples were stored for $24 \mathrm{~h}$ at $20^{\circ} \mathrm{C}$ before centrifuging at $3500 \mathrm{rpm}$ for $15 \mathrm{~min}$. The excess of water or oil was decanted and the tubes inverted for $1 \mathrm{~h}$ at $20^{\circ} \mathrm{C}$. The tubes were then weighed and dried at $105^{\circ} \mathrm{C}$ to constant weight. The WHC was expressed as the grams water held by $1 \mathrm{~g}$ of sample. The $\mathrm{OHC}$ was expressed as the grams of oil held by $1 \mathrm{~g}$ of sample.

\section{Statistics}

All statistical analyses were performed using ANOVA Microsoft Excel.

\section{RESULTS AND DISCUSSION}

\section{Characterization of plant material}

The detailed carbohydrate analysis of water extracts obtained from vegetable parts of black salsify was summarized (Table 1). In leaves, typically consumed as salads, only sucrose, glucose, and fructose were found. The level of sucrose $(3.44 \mathrm{~g} / 100 \mathrm{~g} \mathrm{dw})$ was higher than this of monosaccharides. Any fructooligosaccharides were not detected in leafy samples. However, the roots showed significant content of inulin $(22.6 \mathrm{~g} / 100 \mathrm{~g} \mathrm{dw})$ and 1-kestose $6.25 \mathrm{~g} / 100 \mathrm{~g}$ (Table 1). The reported in the current study results were in the range of $8-21 \%$, but lower than reports of $37-38 \%$ [27]. It was previously reported that total inulin content was $21.2 \%$ dry weight (or $4.2 \%$ fresh) [13]. Therefore, our findings for inulin content in the roots of this vegetable source coincided with literature $[13,27]$. However, contrary to the report for the presence of inulin in leaves, any fructans or inulins were not detect, as well as nystose in the roots [13]. The sucrose values were in a good agreement with data for fresh salsify (kestose $=8.1 \%$ fw and sucrose 
Table 1: Quantities of sugars and inulin in vegetal parts of black salsify (Scorzonera hispanica L.), g/100 g dw

\begin{tabular}{llllll}
\hline Vegetal parts & Inulin & Nystose & Kestose & Sucrose & Glucose \\
\hline Leaves & Absent & Absent & Absent & $3.44 \pm 0.21$ & $0.21 \pm 0.02$ \\
Roots & $22.64 \pm 0.21$ & Absent & $6.52 \pm 0.20$ & $12.80 \pm 0.05$ & $1.37 \pm 0.05$ \\
\hline
\end{tabular}

$12.8 \% \mathrm{fw}$, respectively) [13]. The reported level for fructose content $(1.98 \mathrm{~g} / 100 \mathrm{dw})$ in roots was lower than reported by Van Loo et al. [13].

\section{Characterization of inulin from black salsify}

The characteristics of inulin from black salsify roots were summarized in Table 2. The isolated inulin presented slightly sweet, white substance with high yield (20\%), and purity (70\%). The purity of obtained inulin was tested by HPLC-RID analysis (Fig. 1).

The HPLC-RID chromatogram of inulin showed one single peak. The retention time of the investigated substance $\left(t_{R}=5.85 \mathrm{~min}\right)$ coincided with this of chicory Raftiline inulin ( $\mathrm{DP}=22)$ used as a reference. Minor amounts of kestose and sucrose were found that could be explained with separation mode or as a result of heating during extraction of inulin.

The reducing groups were not higher than $1.2 \%$ (Table 2). This value was lower than inulin obtained from elecampane and common chicory with glucose content of $2.2-2.6 \%[16,17]$. The average DP was calculated to be 17 that characterized it as inulin with medium chain length (Table 2). It is well-known that the DP of inulin depends on different factors: plant species, climate and growing conditions, harvesting maturity, and storage time after harvest $[15,19]$.

The pharmacological properties also depend mainly on their DP [6]. The general correlation is as follows: a higher average DP means a higher biological activity of the inulin. Therefore, in this study, isolated inulin was characterized with DP 17 and can be classified as $\beta$-inulin that produced by addition of ethanol or by freeze thawing. The isolated in this study inulin was obtained by ethanol precipitation. This form is readily soluble in water at room temperature. Moreover, its DP is near to alpha-1 isoform (DP 19-20) according to the new classification [5]. High-molecular-weight inulin (DP 10-65), is fermented twice slower than low polymerized inulin, saved the metabolic activity of the improved microflora in the colon [15].

Blecker et al. [34] showed the dependence between DP and inulin melting temperature. Melting temperature reported in this study (Table 2) was similar to reported between ones 165 and $183^{\circ} \mathrm{C}$ [34].

In the current study, HPLC SEC-RI analysis was used for the determination of $\mathrm{Mw}, \mathrm{Mn}$, and the polydispersity index of isolated inulin from black salsify roots (Table 2). The HPLC-SEC chromatogram (Fig. 2) showed one single symmetric peak, suggesting that inulin was purified completely and presented narrow molecular weight distribution of inulin with polydispersity index 1.04 .

The extraction conditions (i.e., temperature, $\mathrm{pH}$, and time) and the purification methods also can be affected DP of inulin [13, 16-19].

\section{Functional properties}

Moreover, the DP and polydispersity index of an oligo- or poly-saccharide influence the physicochemical properties to a large extent [34]. The isolated inulin from the black salsify roots possessed good water solubility and low swelling ability only $2 \mathrm{ml} / \mathrm{g}$ sample. Similar swelling ability possessed inulin from agave and chicory [36]. However, WHC of this inulin was a quite low and absorbed $0.5 \mathrm{~g}$ of water per gram samples. These functional properties were compared with commercial inulin standard from chicory (Raftiline HPX, Beneo, Orafti) with DP 22-25 inulin. In addition, in the current study, this chicory inulin showed the following characteristics: $1.1 \mathrm{ml} / \mathrm{g}$ sample (swelling properties), water-holding capacity $1.6 \mathrm{~g}$ water/g sample, and OHC $3.5 \mathrm{~g}$ oil/g sample. In comparison
Table 2: Characterization of inulin isolated by microwave extraction from black salsify (Scorzonera hispanica L.) roots

\begin{tabular}{ll}
\hline Characteristics & Values \\
\hline Yield, \% & $20.0 \pm 1.0$ \\
Purity, \% & $70 \pm 2.0$ \\
Reducing groups, \% & $1.2 \pm 0.1$ \\
Fructose content, \% & $50 \pm 3.0$ \\
Average degree of polymerization & 17 \\
Weight molecular weight $(\mathrm{Mw}), \mathrm{Da}$ & 2729 \\
Number molecular weight $(\mathrm{Mn}), \mathrm{Da}$ & 2616 \\
Polydispersity index & 1.04 \\
Swelling properties, ml/g & $2.0 \pm 0.1$ \\
Water-holding g water/g sample & $0.5 \pm 0.1$ \\
Oil-holding capacity, g oil/g sample & $6.1 \pm 0.5$ \\
Melting point, ${ }^{\circ} \mathrm{C}$ & $168-170$ \\
Solubility at $25^{\circ} \mathrm{C}, \%$ & $94 \pm 2$ \\
Appearance & White \\
Taste & Slightly sweet \\
\hline
\end{tabular}

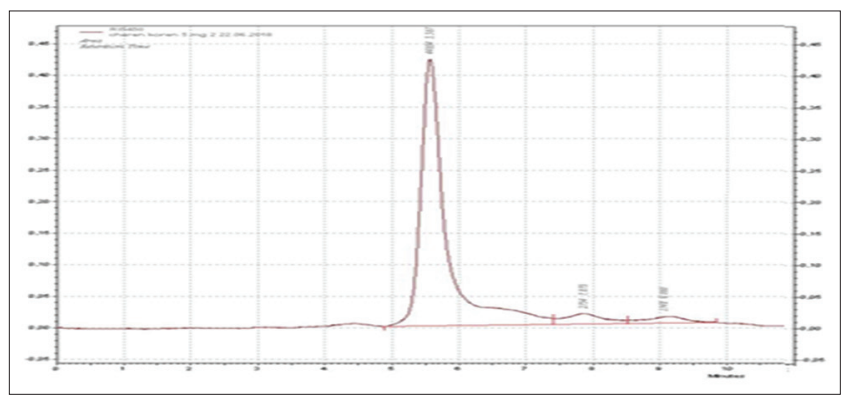

Fig. 1: High-performance liquid chromatography with refractive index detection chromatogram of inulin isolated from black salsify (Scorzonera hispanica L.) roots

with published research for chicory and agave inulin [36], inulin from black salsify possessed higher swelling and OHC (Table 2). Moreover, black salsify inulin with DP 17 showed lower WHC than galactomannan isolated from carob flour [35] and agave inulin [36]. This could be due to particle size, which increased the contact surface between hydrocolloid and water. However, $\mathrm{OHC}$ of the isolated inulin was significantly high ( $6.0 \mathrm{~g}$ oil/g sample) in comparison with chicory inulin ( $3.5 \mathrm{~g}$ oil/g), agave inulin (3.3 oil g/g) [36], and other polysaccharides [35]. The stabilization ability of inulin in food products as sauces and mayonnaise could be explained with its good OHC that represents the ability of the product to absorb fats. Therefore, inulin from S. hispanica L. demonstrated good OHC higher than WHC (Table 2). These results can be useful for future application of inulin from the black salsify roots as stabilizer in oils and/ or lipid-soluble components in food and pharmaceutical formula.

\section{FTIR spectroscopy}

The FT-IR spectrum of inulin from black salsify (S. hispanica L.) roots contained typical bands [37-40] for inulin-type fructans (Table 3 and Fig. 3). This is the first report for spectral characterization of inulin obtained from the black salsify roots.

The detailed bands assignment was summarized in Table 3 .

The broadband at $3300 \mathrm{~cm}^{-1}$ was assigned with the typical stretching vibrations indicated the presence of hydroxyl groups $(-\mathrm{OH})$ of 


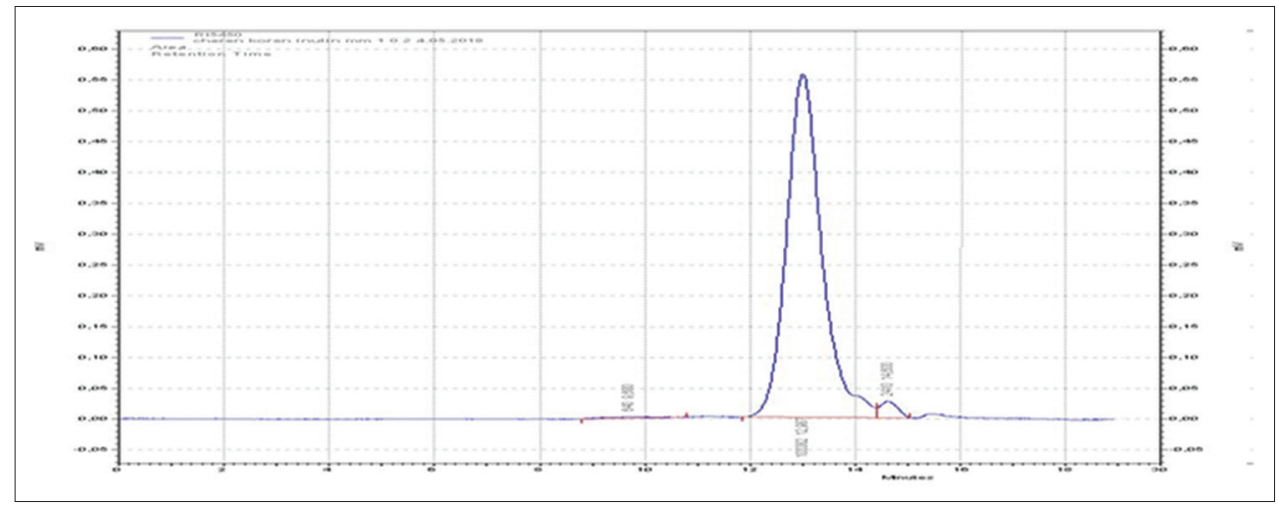

Fig. 2: High-performance liquid chromatography-size-exclusion chromatogram of molecular weight distribution of inulin isolated from black salsify (Scorzonera hispanica L.) roots

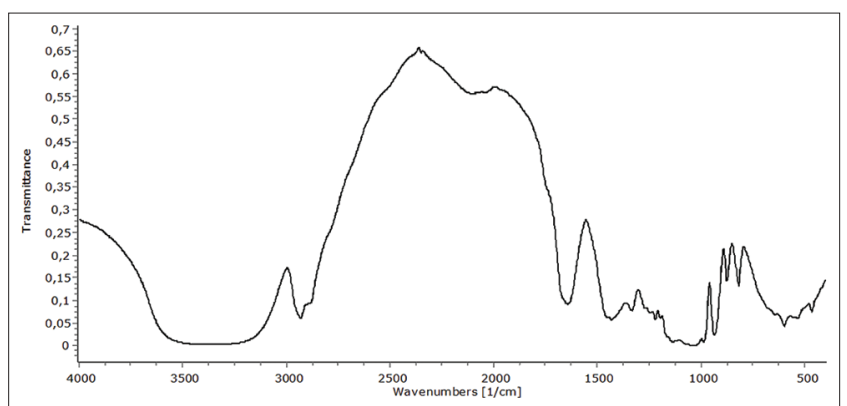

Fig. 3: Fourier transformed infrared spectra of inulin obtained from black salsify (Scorzonera hispanica L.) after microwave irradiation

carbohydrates [41,42] and was connected with inter- and intramolecular hydrogen bonds. The small bands at around $2931 \mathrm{~cm}^{-1}$ and $2889 \mathrm{~cm}^{-1}$ were assigned with symmetric and asymmetric stretching vibrations of $\mathrm{C}-\mathrm{H}$ [37-40] from methylene groups. One band at $1643 \mathrm{~cm}^{-1}$ was appeared that was not specific for inulin, and it was assigned with absorption of water because of its hygroscopic properties of this homopolysaccharide. In the region between 1500 and $900 \mathrm{~cm}^{-1}$ bands typical for C-C stretching in pyranose ring, C-O and $\mathrm{C}-\mathrm{O}-\mathrm{C}$ deformation modes (Fig. 3) were appeared. The bands at $1132 \mathrm{~cm}^{-1}$ were characteristic for C-O-C ring stretching vibrations and the bands at $1027 \mathrm{~cm}^{-1}$ were assigned with C-O stretching vibrations. The band at $935 \mathrm{~cm}^{-1}$ was assigned with $\alpha$-D-Glc $p$ residue in carbohydrate chain [38]. The bands at 873 and $818 \mathrm{~cm}^{-1}$ confirmed $\mathrm{CH}_{2}$ ring vibration of $\beta$-anomer and the presence of 2-ketofuranose [39]. Similar bands were reported for inulin from elecampane, chicory, dahlia, and Jerusalem artichoke as previously described [16-19,43]. Therefore, the isolated polysaccharide from the roots of black salsify was characterized as inulin.

\section{CONCLUSION}

For the first time, inulin was isolated by MAE from black salsify roots, and further spectral and physicochemical characterizations were done. Inulin was evaluated as the major component of the black salsify roots in high yields $(20 \% \mathrm{dw})$ and good purity. Inulin was characterized as middle chained with average DP 17 . These characteristics are of the main interest because of the important functional properties of inulin, related to prebiotics, dietary fiber, in control of lipid metabolism, diabetes, and immunomodulation. The standardization and the chemical characterization of inulin from black salsify approved this plant as a significant source of inulin for future application in food technology and pharmaceutical industry. Its promising $\mathrm{OHC}$ demonstrated potential application of inulin from black salsify in lipid-containing food and pharmaceutical formulas.
Table 3: Assignment of characteristic bands in Fourier transformed infrared spectrum of inulin isolated from black salsify (Scorzonera hispanica L.)

\begin{tabular}{ll}
\hline $\begin{array}{l}\text { Bands, } \\
\mathbf{c m}^{-1}\end{array}$ & Assignment [37-40] \\
\hline 3369 & Hydrogen-bonded O-H stretching vibrations; H-bonds \\
2931 & $v \mathrm{C}-\mathrm{H}_{\text {as }}\left(\mathrm{CH}_{2}\right)$ \\
2889 & $v \mathrm{C}-\mathrm{H}_{\mathrm{s}}\left(\mathrm{CH}_{2}\right)$ \\
1643 & Absorption of water \\
1431 & $v \mathrm{C}-\mathrm{Hs}\left(\mathrm{CH}_{2}\right)$ in pyranosyl ring, $\beta \mathrm{o}-\mathrm{H}(\mathrm{OH})$ \\
1332 & $\beta \mathrm{O}-\mathrm{H}(\mathrm{OH})$ \\
1220 & $\beta \mathrm{O}-\mathrm{H}(\mathrm{OH})$ \\
1134 & $v \mathrm{C}-\mathrm{O}-\mathrm{C}_{\text {as }}(\mathrm{C}-\mathrm{O}-\mathrm{C})$, glycoside linkage \\
1027 & $v \mathrm{C}-\mathrm{O}(\mathrm{C}-\mathrm{O})$ \\
986 & $v \mathrm{C}-\mathrm{O}(\mathrm{C}-\mathrm{O})$ \\
935 & $\alpha-\mathrm{D}-\mathrm{Glc} p$ residue in chain \\
873 & $\rho \mathrm{CH} \mathrm{H}_{2}$ in ring, $\beta$-anomer bendings C1-H, ring vibration \\
& of $(2-$-ketofuranose $)$ \\
818 & 2 -ketose (pyranosyl of furanosyl ring) \\
\hline
\end{tabular}

\section{AUTHORS CONTRIBUTION}

The author conducted the research and wrote the article.

\section{CONFLICTS OF INTEREST}

The author declares that they have no conflicts of interest.

\section{REFERENCES}

1. Imran S, Gillis B, Kok SM, Harding SE, Adams GG. Application and use of inulin as a tool for therapeutic drug delivery. Biotechnol Genet Eng 2013;28:33-46.

2. Chi ZM, Zhang T, Cao TS, Liu XY, Cui W, Zhao CH. Biotechnological potential of inulin for bioprocesses. Biores Technol 2011;102:4295-303.

3. Sinha R, Kumria R. Polysaccharides in colon-specific drug delivery. Int J Pharmaceut 2001;22:419-38.

4. Petrovsky N. Novel human polysaccharide adjuvants with dual Th1 and Th2 potentiating activity. Vaccine 2006;24:26-9.

5. Cooper PD, Barclay TG, Ginic-Markovic M, Petrovsky N. The polysaccharide inulin is characterized by an extensive series of periodic isoforms with varying biological actions. Glycobiology 2013;23:1164-74.

6. Barclay T, Ginic-Markovic M, Cooper P, Petrovsky N. Inulin-a versatile polysaccharide with multiple pharmaceutical and food chemical uses. J Excip Food Chem 2010;1:27-50.

7. Molteni L. Dextran and inulin conjugates as drug carriers. Methods Enzymol 1985;112:285-98

8. Beirão-da-Costa $\mathrm{S}$, Duarte $\mathrm{Cl}$, Bourbon I, Pinheiro A, Januário $\mathrm{M}$, Vicente A, et al. Inulin potential for encapsulation and controlled delivery of oregano essential oil. Food Hydrocoll 2013;33:199-206.

9. Spizzirri G, Altimari I, Puoci F, Parisi O, Iemma F. Innovative antioxidant thermo-responsive hydrogels by radical grafting of catechin on inulin chain. Carbohydr Polym 2011;84:517-23. 
10. Stojanovic R, Belscak-Cvitanovic A, Manojlovic V, Komes D, Nedovic V, Bugarski B. Encapsulation of thyme (Thymus serpyllum L.) aqueous extract in calcium alginate beads. J Sci Food Agric 2012;92:685-96.

11. Ravi V, Pr K, Siddaramaiah TM. Novel colon targeted drug delivery system using natural polymers. Indian J Pharm Sci 2008;70:111-3.

12. Wada T, Sugatani J, Terada E, Ohguchi M, Miwa M. Physicochemical characterization and biological effects of inulin enzymatically synthesized from sucrose. J Agric Food Chem 2005;53:1246-53.

13. Van Loo J, Coussement P, De Leenheer L, Hoebregs H, Smits G. On the presence of inulin and oligofructose as natural ingredients in the Western diet. Crit Rev Food Sci Nutr 1995;35:525-52.

14. Zhu Z, Bals O, Grimi N, Vorobiev N. Pilot scale inulin extraction from chicory roots assisted by pulsed electric fields. Int J Food Sci Tech 2012;47:1361-8.

15. Kriukova Y, An JA, Ilyinska N, Krotkiewski H, Gontova T, Evtifeyeva O, et al. Chain length distribution of inulin from dahlia tubers as influenced by the extraction method. Int J Food Prop 2017;20:S3112-22.

16. Petkova N, Ognyanov $\mathrm{M}$, Denev P. Isolation and Characterization of Inulin Obtained from Taproots of Common Chicory (Cichorium intybus L.). Vol. 39. Bulgaria: University of Plovdiv "Paisii Hilendarski” Bulgaria Scientific Papers; 2014;39:25-34.

17. Petkova N, Ognyanov M, Todorova M, Denev P. Ultrasound-assisted extraction and characterization of inulin-type fructan from roots of elecampane (Inula helenium L.). Am Soc Nutr 2015;1:225-35.

18. Temkov M, Petkova N, Denev P, Krastanov A. Characterization of inulin from Helianthus tuberosus L. obtained by different extraction methods - Comparative study. Sci Works Univ Food Technol 2015;52:461-4.

19. Petkova N, Sherova G, Denev P. Characterization of inulin from dahlia tubers isolated by microwave and ultrasound-assisted extractions. Int Food Res J 2018. (In Press).

20. Portal C. Available from: http://cichorieae.e-taxonomy.net/ portal/cdm_dataportal/taxon/e 7cfe0d5-bafe-4be8-b248e40037c4cb08\#footnote-N -Chicore Portal. [Last accessed on 2018 Jun 21].

21. Shih C, Scorzonera KN. In: Wu ZY, Raven PH, Hong DY, editors. Flora of China. Vol. 21. St. Louis: Science Press, Beijing and Missouri Botanical Garden Press; 2011. p. 198.

22. Pereira IP, Dias AS, Dias LS. Responses of germination and early growth of scorzonera (Scorzonera hispanica L.) to $\mathrm{pH}$, mineral deficiencies and growth substrates. Bulg J Agric Sci 2014;20:1195-201.

23. Mavrodiev EV, Edwards CE, Albach DE, Gitzendanner MA, Soltis PS, Soltis DE. Phylogenetic relationships in subtribe Scorzonerinae (Asteraceae: Cichorioideae: Cichorieae) based on ITS sequence data. Taxon 2004;53:699-712.

24. Dolota A, Dabrowska B. The nutritive value of theleaves of several scorzonera (Scorzonera hispanica L.) cultivars. Folia Univ Agric Stetin Agricult 2004;239:63-8.

25. Jeffrey C. Compositae (Asteraceae). In: Hanelt P, editor. Mansfeld's Encyclopedia of Agricultural and Horticultural Crops (Except Ornamentals). Berlin: Springer-Verlag GmbH, Heidelberg; 2001. p. 2066.

26. Nuez F, Bermejo JE. Neglected horticultural crops. In: Bermejo JE, León J, editors. Neglected Crops: 1492 from a Different Perspective.
Roma: FAO Viale delle Terme di Caracalla; 1994. p. 303-32.

27. Bashta A, Ivchuk N, Bashta O. Yacón and scorzonera as functional enrichment of food. Ukrainian J Food Sci 2015;3:13-22.

28. Vulsteke G, Calus A. Influence of variety, date of harvestand storage time on factors connected with the crystallizationon canned scorzonera (Scorzonera hispanica). Plant Food Hum Nutr 1990;40:149-66.

29. Dolota A, Dabrowska B. Raw fibre and inulin contentin roots of different scorzonera cultivars (Scorzonera hispanica L.) depending on cultivation method. Folia Hort 2004;16:31-7.

30. Singh R, Singh R. Prodiction of fructooligosaccharides from inulin by endo-inulinases and their prebiotic potential. Food Technol Biotech 2010;48:435-50.

31. Petkova N, Vrancheva R, Denev P, Ivanov I, Pavlov A. HPLC-RID method for determination of inulin and fructooligosacharides. Am Soc Nutr 2014;1:99-107.

32. Lever M. A new reaction for colorimetric determination of carbohydrates. Anal Biochem 1972;47:273-9.

33. Murdzheva D, Petkova N, Todorova M, Vasileva I, Ivanov I, Denev P. Microwave-assisted synthesis of methyl esters of alginic acids as potential drug carrier. Int J Pharm Clin Res 2016;8:1361-8.

34. Blecker CS, Chevalier JP, Fougnies C, Van Herck JC, Deroanne C, Paquot M. Characterisation of different inulin samples by DSC: Influence of polymerisation degree on melting temperature. J Therm Anal Calorim 2003;71:215-24.

35. Petkova N, Petrova I, Ivanov I, Mihov R, Hadjikinova R, Ognyanov M, et al. Nutritional and antioxidant potential of carob (Ceratonia siliqua) flour and evaluation of functional properties of its polysaccharide fraction. Int J Pharm Sci Res 2017:9:2189-95.

36. Bouaziz MA, Rassaoui R, Besbes S. Chemical composition, functional properties, and effect of inulin from tunisian Agave americana L. leaves on textural qualities of pectin gel. J Chem 2014;2014:1-11.

37. Grube M, Bekers M, Upite D, Kaminska E. Infrared spectra of some fructans. J Spectrosc 2002;16:289-96

38. Heize T, Liebert T, Koshella A. Esterification of Polysaccharides. Berlin, Heidelberg: Springer Verlag; 2006.

39. Tipson RS. Infrared Spectroscopy of Carbohydrates. A Review of the Literature. Washington, DC: NBS Monograph; 1968. p. 110.

40. Samanta (Koruri) SH, Banerjee D, Chowdhury R, Bhattacharya P. Studies on prebiotic food additive (inulin) in Indian dietary fibre sources-garlic (Allium sativum), wheat (Triticum spp.), oat (Avena sativa) and Dalia (bulgur). Int J Pharm Pharm Sci 2014;6:278-82.

41. Uwah TO, Akpabio EI, Ekpa DE, Akpabio AE, Godwin J. Investigations into the physicochemical and compaction characteristics of modified starch of Discorea alata using diclofenac sodium tablet. Int J Pharm Pharm Sci 2018;10:66-74

42. Thomas D, Latha MS, Thomas KK. Evaluation of the antibacterial activity of calcium alginate beads modified with ethanolic extract of Adhatoda vasica leaf extract on Staphylococcus aureus and Escherichia coli. Asian J Pharm Clin Res 2018;11:68-70.

43. Taani B, Khanfar M, Alsuod OA. Enhancement of the release of curcumin by the freeze drying technique using inulin and neusilin as carriers. Int J App Pharm 2018;10:42-8. 